\title{
Solution for Skin-scratch Test Dosage
} Form

National Cancer Institute

\section{Source}

National Cancer Institute. Solution for Skin-scratch Test Dosage Form. NCI Thesaurus.

Code C149930.

Liquid sterile preparation consisting of a solution containing an allergen product intended for diagnostic use in a skin-scratch test. 